\title{
Estimation of Ready Queue Processing Time under Usual Group Lottery Scheduling (GLS) in Multiprocessor Environment
}

\author{
D. Shukla \\ Deptt. of Statistics \\ Dr.H.S.Gour Central University, \\ Sagar (M.P), INDIA
}

\author{
Anjali Jain \\ Deptt. of Computer Sc. and Applications \\ Dr.H.S. Gour Central University \\ Sagar (M.P.), INDIA
}

\author{
Amita Choudhary \\ Deptt. of Computer Sc. and \\ Applications \\ DAVV, Indore (M.P.), INDIA
}

\begin{abstract}
Lottery scheduling is one of the useful techniques for managing the process queue by the scheduler. The significant feature it has the random selection of jobs in a probability manner so that various existing probability models could be used to derive interesting results. One of possible applications incorporated herewith by using probability based sampling models to estimate total time required to process all the jobs in a ready queue. A new scheduling scheme is designed named as Group Lottery Scheduling (GLS) and using this the total possible ready queue processing time is predicted in multi-processor environment. There are two variants involved in GLS as Type-I allocation and Type-II allocation of jobs to the multi-processors whose variabilities are compared. A numerical example is incorporated to support the theoretical findings.
\end{abstract}

Keywords: Scheduling, Lottery Scheduling, Group Lottery Scheduling (GLS), Estimator and Sampling.

\section{INTRODUCTION}

The CPU scheduling design and analysis is one of the most burning areas of research where new scheme appears like betterment over others. Some well known scheduling schemes are FIFO, Round Robin, Priority Scheduling, Multilevel queue scheduling, Fair queue scheduling etc. In most of these, job selection is performed in specific manner. Lottery scheduling is different where job selection from ready queue is through a random procedure. In general, every job has an equal chance of being represented in the processor. Carl et al. [1] discussed the proportional share resource management technique in lottery scheduling. David et al. [3] presented the specialization matching methodology in context to lottery scheduling. Shukla et al. [7] discussed a new variant of Lottery scheduling like SL Scheduling where the job selection is performed in random as well as in systematic manner both. The drawback with this is that it generates high variability in predicted estimates obtained and does not take into account the size measure of the process. Shukla and Jain [5], [6] worked over multi-level queue scheduling with application of probability models in analysis. Sampling techniques and its wide applications are in [2] and [9]. Description of methodological part of scheduling is in [9], [10] and [11]. Raz et al. [4] presented procedure of deciding priorities among jobs by maintaining fairness in selection procedure. The problem of ready queue processing time estimation (or prediction) is required in case when sudden breakdown of system appears. System manager wants to know how much time needed to process remaining jobs in the ready queue after occurrence of breakdown. This estimate helps to manage the various backup resources related to computer system to safeguard the remaining jobs. This paper presents a technique of processing time estimation of the entire ready queues based on processed jobs as a sample, using sampling technique models.

\section{MOTIVATION}

Suppose processes in a ready queue are heterogeneous nature in terms of size measure, type variant and requirement indifferentiation. Then the random selection in lottery scheduling is not a fruitful idea, because a small size job would have the same probability as a larger one. The one-type job priority shall be same as other-type. It is better, in this scenario, to use grouping of processes in the ready queue as per measure of certain characteristics (like size or type or need). Deriving motivation from this, we propose Group Lottery Scheduling (GLS) scheme for process selection and processing time estimation method.

\section{GL SCHEDULING SCHEME}

a) Let there are $\mathrm{r}$ processors $\mathrm{Q}_{1}, \mathrm{Q}_{2}, \mathrm{Q}_{3} \ldots \ldots \mathrm{Q}_{\mathrm{r}}$, each draws random samples of jobs from corresponding ready queues. All processes in $i^{\text {th }}$ ready queue are homogeneous with respect to certain characteristic whereas in usual waiting queue they are present in any order of size measure.

b) The CPU restricts a session of time duration T. All $N$ ready queue processes are divided into $\mathrm{r}$ groups each of size containing $N_{i}$ processes $\left(\Sigma N_{i}=N\right)$. This division is based on size measure.

c) All $N$ processes are allotted token of numbers and each processor draws a random number. If the random number of $i^{\text {th }}$ processor matches with the allotted random number to $j^{\text {th }}$ process of $i^{\text {th }}$ group then it is selected for processing ( $\mathrm{i}=1,2$, $\left.3 \ldots . . \mathrm{r}, \mathrm{j}=1,2,3 \ldots . . N_{i}\right)$.

d)Let $\mathrm{k}_{1}$ processes received from first group, $\mathrm{k}_{2}$ processes received from second group and so on, the $\mathrm{k}_{\mathrm{r}}^{\text {th }}$ received processes from $\mathrm{r}^{\text {th }}$ group in random manner using lottery procedure $\left[\Sigma k_{i}=k\right]$ in a session of fixed time $\mathrm{T}$ where $\mathrm{k}$ is the total sample size. 
e) At the end of a session, the CPU provides processed time data for $\mathrm{k}_{1}, \mathrm{k}_{2}, \mathrm{k}_{3} \ldots . \mathrm{k}_{\mathrm{r}}$ jobs as $\left(\mathrm{t}_{11}, \mathrm{t}_{12}, \mathrm{t}_{13} \ldots . ., \mathrm{t}_{21}, \mathrm{t}_{22}, \mathrm{t}_{23} \ldots\right.$, $\left.. \mathrm{t}_{\mathrm{i} 1}, \mathrm{t}_{\mathrm{i} 2}, \mathrm{t}_{\mathrm{i} 3} \ldots\right)$ where $\mathrm{t}_{\mathrm{ij}}$ are the time consumed by $j^{\text {th }}$ job processed by the $i^{\text {th }}$ processor. The grand average of time of general queue is $t^{*}=\frac{1}{k} \sum_{i} \sum_{j} t_{i j}$

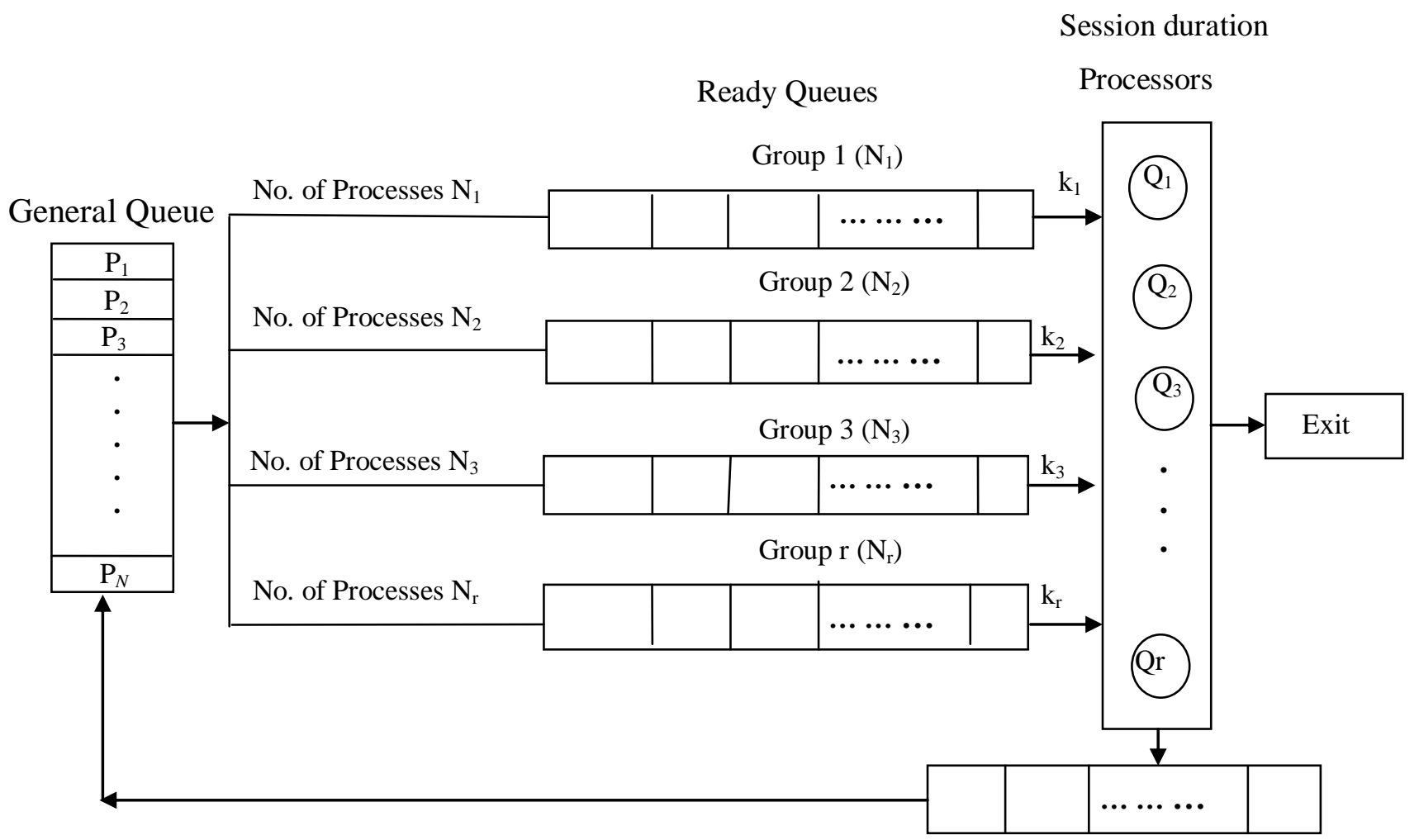

Blocked or Suspended queue

Fig. 3.1: Ready Queue processing structure under Group Lottery Scheduling (GLS)

\section{ESTIMATION METHOD OF READY QUEUE PROCESS TIME IN A SESSION IN GLS.}

Let processed time $t_{i j}$ be expressed in terms of group division as $t^{\text {th }}$ time consumed by the processor to process the $j^{\text {th }}$ job coming from $i^{\text {th }}$ group. Then $t_{i}^{\prime}=\frac{1}{k_{i}} \sum_{j=1} t_{i j}$ is mean of time units of coming from $i^{\text {th }}$ group sample. Let $W_{i}=\frac{N_{i}}{N}$ be the weight index of $i^{\text {th }}$ group. An estimator for estimating average time of ready queue is $\bar{t}=\sum_{i-1}^{r} w_{i} t_{i}^{\prime}$.

Let $S^{2}$ be the time mean square of the entire queue time variations whereas $S_{i}^{2}$ is the time mean square of $i^{\text {th }}$ group jobs. We get general variability expression for GLS as

$$
\begin{aligned}
& V(\bar{t})_{G L S}=\sum_{i=1}^{r}\left(\frac{1}{k_{i}}-\frac{1}{N_{i}}\right) W_{i}^{2} S_{i}^{2} \\
& S^{2}=(N-1)^{-1} \sum_{i=1}^{r} \sum_{j}^{N_{i}}\left(t_{i j}-\bar{t}\right)^{2} ; \bar{t}=(N)^{-1} \sum_{i=1}^{r} \sum_{j=1}^{N_{i}} t_{i j} \\
& S_{i}^{2}=\left(N_{i}-1\right)^{-1} \sum_{i=1}^{r}\left(t_{i}^{\prime}-\bar{t}\right)^{2}
\end{aligned}
$$

The total predicted ready queue processing time is $t^{\prime \prime}=N \bar{t}$

\subsection{Allocation Problem}

\subsubsection{Type- I Allocation}

Among total $r$ processors, $k_{1}, k_{2}, k_{3}, \ldots . . ., k_{r}$ are number of different allocations of jobs to processors in a session $\mathrm{T}$, it is hard 
to obtain suitable number of choice of $k_{i}$ such that $\sum_{i=1}^{r} k_{i}=k$. We propose an allocation method named as Type-1 allocation where $k_{i} \alpha N_{i}$.

The logic for this allocation is to choose larger number of processes if the group is large. Now we write $k_{i}=\mathrm{M} N_{i \text { where }}$ $M$ is a constant.

Then $\quad \sum_{i=1}^{r} k_{i}=\sum_{i=1}^{r} M N_{i} \quad\left[\because \sum_{i=1}^{r} k_{i}=k\right]$

$$
\text { and } \quad M=\frac{k}{N}
$$

Put the value of $M$ in above equation, we get

$$
k_{i}=\mathrm{kW}_{i}
$$

It is Type-I allocation where $i^{\text {th }}$ processor is allowed to choose $\mathrm{K}_{\mathrm{i}}$ jobs from $i^{\text {th }}$ group in a session $\mathrm{T}$ in random manner.

\subsubsection{Type-II Allocation}

Let

$$
\begin{aligned}
& k_{i} \alpha N_{i} \text { and } k_{i} \alpha \mathrm{S}_{i} \\
& \Rightarrow k_{i} \alpha N_{i} S_{i} \\
& \Rightarrow k_{i}=\mathrm{M} N_{i} S_{i} \\
& \Rightarrow \sum k_{i}=\mathrm{M} \sum N_{i} S_{i} \\
& \Rightarrow \mathrm{M}=\frac{k}{\sum N_{i} S_{i}}
\end{aligned}
$$

Put the value of $\mathrm{M}$ in above equation, we get Type-II allocation

$$
\begin{aligned}
& \Rightarrow k_{i}=\frac{k N_{i} S_{i}}{\sum_{i=1}^{r} N_{i} S_{i}} \\
& \Rightarrow k_{i}=\frac{k W_{i} S_{i}}{\sum_{i=1}^{r} W_{i} S_{i}}
\end{aligned}
$$

In this the $i^{\text {th }}$ processors is allowed to choose $\mathrm{K}_{\mathrm{i}}$ in a session $\mathrm{T}$ as per (4.1.2)

\subsection{Variance under Type-I and Type-II allocation:}

The general expression of variance of GLS is:

$V(\bar{t})_{G L S}=\sum_{i=1}^{r}\left(\frac{1}{k_{i}}-\frac{1}{N_{i}}\right) W_{i}^{2} S_{i}^{2}$

\subsubsection{Variance under Type- 1 allocation:}

$$
V(\bar{t})_{G L S}=\sum_{i=1}^{r} \frac{W_{i}^{2} S_{i}^{2}}{k_{i}}-\sum_{i=1}^{r} \frac{W_{i}^{2} S_{i}^{2}}{N_{i}}
$$

By putting the value of $k_{i}$ from (4.1.1)

$$
\begin{aligned}
& \Rightarrow \sum_{i=1}^{r} \frac{W_{i}^{2} S_{i}^{2}}{\left(\frac{k}{N}\right) N_{i}}-\sum_{i=1}^{r} \frac{W_{i}^{2} S_{i}^{2}}{N_{i}} \\
& \Rightarrow \sum_{i=1}^{r} \frac{N W_{i}^{2} S_{i}^{2}}{k N_{i}}-\sum_{i=1}^{r} \frac{W_{i}^{2} S_{i}^{2}}{N_{i}} \\
& \Rightarrow \frac{N}{k} \sum_{i=1}^{r} \frac{W_{i}^{2} S_{i}^{2}}{N_{i}}-\sum_{i=1}^{r} \frac{W_{i}^{2} S_{i}^{2}}{N_{i}} \\
& \Rightarrow \frac{N}{k} \sum_{i=1}^{r} \frac{N_{i}^{2} S_{i}^{2}}{N^{2} N_{i}}-\sum_{i=1}^{r} \frac{N_{i}^{2} S_{i}^{2}}{N^{2} N_{i}}\left(\because W_{i}=\frac{N_{i}}{N}\right) \\
& \Rightarrow \frac{1}{k} \sum_{i=1}^{r} N_{i} S_{i}^{2}-\frac{1}{N^{2}} \sum_{i=1}^{r} N_{i} S_{i}^{2} \\
& \Rightarrow \frac{1}{k} \sum_{i=1}^{r} W_{i} S_{i}^{2}-\frac{1}{N} \sum_{i=1}^{r} W_{i} S_{i}^{2} \\
& \Rightarrow \sum_{i=1}^{r} W_{i} S_{i}^{2}\left(\frac{1}{k}-\frac{1}{N}\right) \\
V(\bar{t})_{\text {Type-I }}= & \left(\frac{1}{k}-\frac{1}{N}\right) \sum_{i=1}^{r} W_{i} S_{i}^{2}
\end{aligned}
$$

\subsubsection{Variance under Type-II allocation:}

By putting the value of $k_{i}$ from (4.1.2)

$$
\begin{gathered}
V(\bar{t})_{G L S}=\sum_{i=1}^{r} \frac{\left(\sum N_{i} S_{i}\right) W_{i}^{2} S_{i}^{2}}{k N_{i} S_{i}}-\sum_{i=1}^{r} \frac{W_{i}^{2} S_{i}^{2}}{N_{i}} \\
\Rightarrow \frac{\sum N_{i} S_{i}}{k N^{2}} \sum_{i=1}^{r} N_{i} S_{i}-\frac{1}{N^{2}} \sum_{i=1}^{r} N_{i} S_{i}^{2} \\
\Rightarrow\left(\frac{\sum N_{i} S_{i}}{k N}\right)\left(\sum_{i=1}^{r} W_{i} S_{i}\right)-\frac{1}{N} \sum_{i=1}^{r} W_{i} S_{i}^{2} \\
\Rightarrow\left(\frac{\sum W_{i} S_{i}}{k}\right)\left(\sum_{i=1}^{r} W_{i} S_{i}\right)-\frac{1}{N} \sum_{i=1}^{r} W_{i} S_{i}^{2} \\
V(\bar{t})_{\text {Type-II }}=\frac{1}{k}\left(\sum_{i=1}^{r} W_{i} S_{i}\right)^{2}-\frac{1}{N} \sum_{i=1}^{r} W_{i} S_{i}^{2}
\end{gathered}
$$




\section{NUMERICAL ILLUSTRATION}

We have considered 30 processes in general queue and their CPU burst time shown in table 5.1.

Table 5.1: Total Processes with CPU Burst Time in general queue.

\begin{tabular}{|c|c|c|c|c|c|}
\hline Processes & $P_{1}$ & $P_{2}$ & $P_{3}$ & $P_{4}$ & $P_{5}$ \\
\hline CPU Burst Time & 30 & 20 & 112 & 40 & 59 \\
\hline Processes & $P_{6}$ & $P_{7}$ & $P_{8}$ & $P_{9}$ & $P_{10}$ \\
\hline CPU Burst Time & 60 & 33 & 43 & 101 & 69 \\
\hline Processes & $P_{11}$ & $P_{12}$ & $P_{13}$ & $P_{14}$ & $P_{15}$ \\
\hline CPU Burst Time & 138 & 43 & 109 & 26 & 74 \\
\hline Processes & $P_{16}$ & $P_{17}$ & $P_{18}$ & $P_{19}$ & $P_{20}$ \\
\hline CPU Burst Time & 89 & 123 & 67 & 58 & 84 \\
\hline Processes & $P_{21}$ & $P_{22}$ & $P_{23}$ & $P_{24}$ & $P_{25}$ \\
\hline CPU Burst Time & 143 & 29 & 147 & 94 & 131 \\
\hline Processes & $P_{26}$ & $P_{27}$ & $P_{28}$ & $P_{29}$ & $P_{30}$ \\
\hline CPU Burst Time & 79 & 46 & 59 & 72 & 22 \\
\hline
\end{tabular}

\subsection{Under Ready Queue and Group Lottery Scheduling (GLS) Scheme:}

Consider groups having size $\mathrm{N}_{2}, \mathrm{~N}_{2}$ and $\mathrm{N}_{3}$ respectively where $\mathrm{N}=\left(\mathrm{N} 2+\mathrm{N}_{2}+\mathrm{N}_{3}\right)$

Table 5.2: Grouped Processes Structure of three Ready Queues as per Burst Time Homogeneity.

\begin{tabular}{|c|c|c|}
\hline Group 1 & Group 2 & Group 3 \\
\hline$P_{1}(30)$ & $P_{5}(59)$ & $P_{3}(112)$ \\
\hline$P_{2}(20)$ & $P_{6}(60)$ & $P_{9}(101)$ \\
\hline$P_{4}(40)$ & $P_{10}(69)$ & $P_{11}(138)$ \\
\hline$P_{7}(33)$ & $P_{15}(74)$ & $P_{13}(109)$ \\
\hline$P_{8}(43)$ & $P_{16}(89)$ & $P_{17}(123)$ \\
\hline$P_{12}(43)$ & $P_{18}(67)$ & $P_{21}(143)$ \\
\hline$P_{14}(26)$ & $P_{19}(58)$ & $P_{23}(147)$ \\
\hline$P_{22}(29)$ & $P_{20}(84)$ & $P_{25}(131)$ \\
\hline$P_{27}(46)$ & $P_{24}(94)$ & \\
\hline \multirow[t]{3}{*}{$P_{30}(22)$} & $P_{26}(79)$ & \\
\hline & $P_{28}(59)$ & \\
\hline & $P_{29}(72)$ & \\
\hline
\end{tabular}


Table 5.3: Computational Values for Grouped Processes Parameter

\begin{tabular}{|c|c|c|c|}
\hline Numbers of Processes in Group1 $\left(N_{1}\right)$ & 10 & Square of Mean Time for Group $2\left(\bar{Y}_{2}^{2}\right)$ & 62208.00 \\
\hline Numbers of Processes in Group $2\left(N_{2}\right)$ & 12 & Square of Mean Time for Group $3\left(\bar{Y}_{3}^{2}\right)$ & 15750.25 \\
\hline Numbers of Processes in Group $3\left(N_{3}\right)$ & 8 & Total Sum of Squares for Group $1\left(\sum_{i=1}^{10} Y_{i}^{2}\right)$ & 11804 \\
\hline Weight Index for Group $1\left(W_{1}\right)$ & 0.333 & Total Sum of Squares for Group $2\left(\sum_{i=1}^{12} Y_{i}^{2}\right)$ & 63890 \\
\hline Weight Index for Group $2\left(W_{2}\right)$ & 0.400 & Total Sum of Squares for Group $2\left(\sum_{i=1}^{8} Y_{i}^{2}\right)$ & 128018 \\
\hline Weight Index for Group $3\left(W_{3}\right)$ & 0.266 & Mean Square for Group $1\left(S_{1}^{2}\right)$ & 86.8444 \\
\hline Mean Time for Group $1\left(\bar{Y}_{1}\right)$ & 33.20 & Mean Square for Group $2\left(S_{2}^{2}\right)$ & 152.9090 \\
\hline Mean Time for Group $2\left(\bar{Y}_{2}\right)$ & 72.00 & Mean Square for Group $3\left(S_{3}^{2}\right)$ & 288.00 \\
\hline Mean Time for Group $3\left(\bar{Y}_{3}\right)$ & 125.50 & $\begin{array}{l}\text { Variance of Group Lottery Scheduling for } \\
\text { Type-I } \\
{\left[V(\bar{t})_{G L S}\right]_{\text {TypeI }}}\end{array}$ & 27.7817 \\
\hline Square of Mean Time for Group $1\left(\bar{Y}_{1}^{2}\right)$ & 1102.24 & $\begin{array}{l}\text { Variance of Group Lottery Scheduling for } \\
\text { Type-II } \\
\qquad\left[V(\bar{t})_{G L S}\right]_{\text {TypeII }}\end{array}$ & 26.0120 \\
\hline
\end{tabular}

Table 5.4: Computation of Confidence Interval for Type-I GLS

\begin{tabular}{|c|c|c|c|c|c|c|c|}
\hline \multirow{2}{*}{$\begin{array}{c}\text { Random } \\
\text { Sample }\end{array}$} & \multicolumn{3}{|c|}{$\begin{array}{c}\text { Sampled selected with } \\
\text { Processing Time (k=5) }\end{array}$} & Total & $\begin{array}{c}\text { Sampled } \\
\text { Mean }\end{array}$ & $\begin{array}{c}\text { Confidence Interval } \\
\text { for mean Time for } \\
\text { per process }\end{array}$ & $\begin{array}{c}\text { 99\% Confidence Interval } \\
\text { for Total Time for } \\
\text { complete Ready Queue }\end{array}$ \\
\cline { 2 - 5 } & $\begin{array}{c}\text { Group1 } \\
\mathbf{K}_{\mathbf{1}}=(\mathbf{2})\end{array}$ & $\begin{array}{c}\text { Group2 } \\
\mathbf{K}_{\mathbf{2}}=(\mathbf{2})\end{array}$ & $\begin{array}{c}\text { Group3 } \\
\mathbf{K}_{\mathbf{3}}=(\mathbf{1})\end{array}$ & & & & $(275.9,434.05)$ \\
\hline 1. & 30,43 & 60,84 & 138 & 355 & 71 & $(55.18,86.81)$ & $(129.05,394.05)$ \\
\hline 2. & 33,46 & 69,58 & 109 & 315 & 63 & $(25.81,78.81)$ & $(264.9,423.05)$ \\
\hline 3. & 20,46 & 59,72 & 147 & 344 & 68.8 & $(52.98,84.61)$ & $(271.9,430.05)$ \\
\hline 4. & 40,22 & 74,84 & 131 & 351 & 70.2 & $(54.38,86.01)$ & $(261.9,420.05)$ \\
\hline 5. & 43,29 & 79,67 & 123 & 341 & 68.2 & $(52.38,84.01)$ & $(290.9,449.05)$ \\
\hline 6. & 46,20 & 89,72 & 143 & 370 & 74 & $(58.18,89.81)$ & $(208.9,367.05)$ \\
\hline 7. & 30,29 & 59,69 & 101 & 288 & 57.6 & $(41.78,73.41)$ & $(234.9,393.05)$ \\
\hline 8. & 46,26 & 72,58 & 112 & 314 & 62.8 & $(46.98,78.61)$ & $(252.9,411.05)$ \\
\hline 9. & 40,29 & 60,94 & 109 & 332 & 66.4 & $(50.58,82.21)$ & $(267.5,426.05)$ \\
\hline 10. & 20,43 & 79,58 & 147 & 347 & 69.4 & $(53.58,85.21)$ & \\
\hline
\end{tabular}


Table 5.5: Computation of Confidence Interval for Type-II GLS

\begin{tabular}{|c|c|c|c|c|c|c|c|}
\hline \multirow{2}{*}{$\begin{array}{c}\text { Random } \\
\text { Sample }\end{array}$} & \multicolumn{3}{|c|}{$\begin{array}{c}\text { Sampled selected with } \\
\text { Processing Time (k=5) }\end{array}$} & \multirow{2}{*}{ Total } & $\begin{array}{c}\text { Sampled } \\
\text { Mean }\end{array}$ & $\begin{array}{c}\text { Confidence Interval } \\
\text { for mean Time for } \\
\text { per process }\end{array}$ & $\begin{array}{c}\text { 99\% Confidence. Interval } \\
\text { for Total Time for } \\
\text { Complete Ready Queue }\end{array}$ \\
\cline { 2 - 5 } & $\begin{array}{c}\text { Group1 } \\
\mathbf{K}_{\mathbf{1}}=\mathbf{( 1 )}\end{array}$ & $\begin{array}{c}\text { Group2 } \\
\mathbf{K}_{\mathbf{2}}=\mathbf{( 2 )}\end{array}$ & $\begin{array}{c}\text { Group3 } \\
\mathbf{K}_{\mathbf{3}=} \mathbf{( 2 )}\end{array}$ & & & & \\
\hline 1. & 46 & 59,79 & 147,112 & 443 & 88.6 & $(73.3,103.9)$ & $(366.5,519.5)$ \\
\hline 2. & 22 & 60,72 & 131,138 & 423 & 84.6 & $(69.3,99.9)$ & $(346.5,499.5)$ \\
\hline 3. & 26 & 69,58 & 101,123 & 371 & 74.2 & $(58.9,89.5)$ & $(294.5,447.5)$ \\
\hline 4. & 30 & 74,67 & 143,109 & 423 & 84.6 & $(69.3,99.9)$ & $(346.5,499.5)$ \\
\hline 5. & 29 & 89,59 & 147,101 & 425 & 85.0 & $(69.7,100.3)$ & $(348.5,501.5)$ \\
\hline 6. & 26 & 94,60 & 143,112 & 435 & 87.0 & $(71.7,102.3)$ & $(358.5,511.5)$ \\
\hline 7. & 40 & 84,69 & 109,123 & 425 & 85.0 & $(69.7,100.3)$ & $(348.5,501.5)$ \\
\hline 8. & 33 & 72,60 & 131,101 & 367 & 73.4 & $(58.1,88.7)$ & $(290.5,443.5)$ \\
\hline 9. & 29 & 59,94 & 112,147 & 441 & 88.2 & $(72.9,103.5)$ & $(364.5,517.5)$ \\
\hline 10. & 43 & 74,67 & 138,109 & 431 & 86.2 & $(70.9,101.5)$ & $(354.5,507.5)$ \\
\hline
\end{tabular}

Confidence intervals for mean time are computed by $P|\bar{t}-3 \sqrt{V(\bar{t})}, t+3 \sqrt{V(\bar{t})}|=0.99 \%$ where $\bar{t}$ is mean estimated time per job.

\section{GRAPHICAL ANALYSIS}

We present comparision of sample mean time under Type-I and Type-II allocations of entire ready queue.

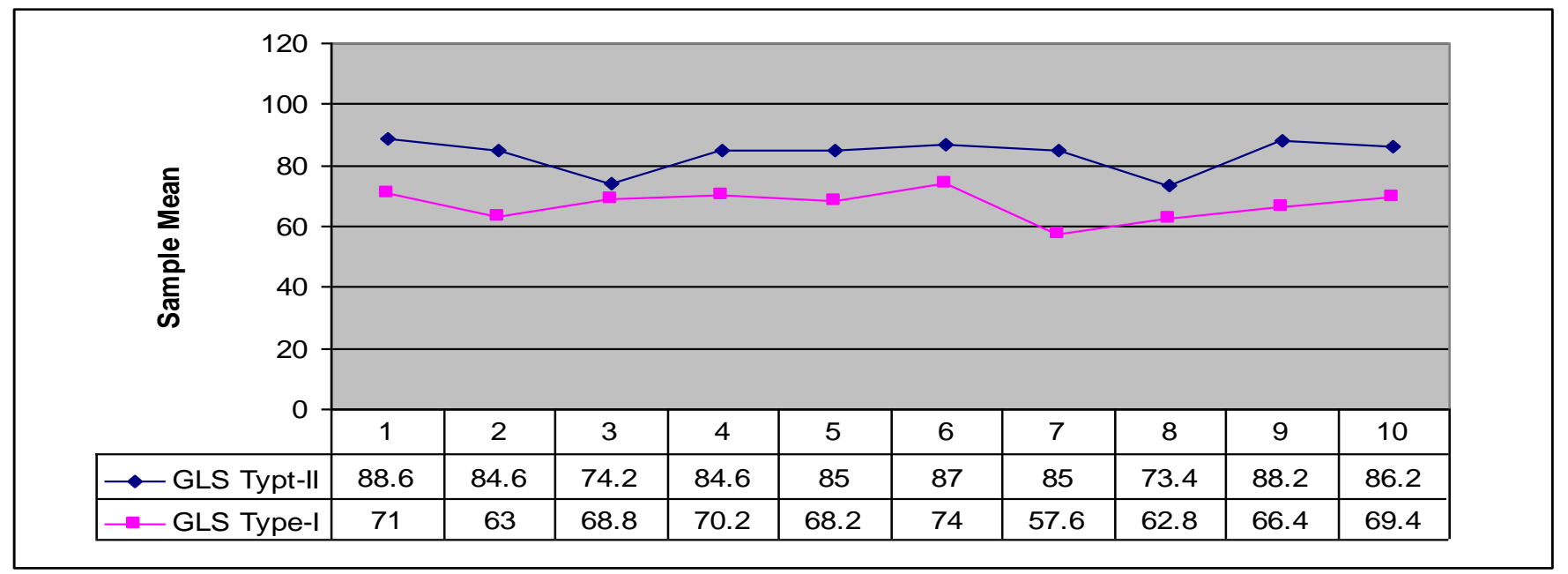

Fig 6.1

\section{CONCLUDING REMARKS}

The paper suggests a modified form of Lottery Scheduling named as Group Lottery Scheduling under multiprocessor Environment. Problem of ready queue processes time prediction is taken into consideration subject to condition of random selection of processes from various groups of ready queue. Two types of allocations suggested as Type-I and Type-II. Both are compared in terms of mean time variances. It is found that Type -II allocation is better than Type-I allocation method because the sample estimates are very much within the $99 \%$ confidence interval and overall variability is lesser. Therefore, instead of usual lottery scheduling if one follows GLS scheme then it is possible to 
estimate the processing time of all $\mathrm{N}$ jobs present in the ready queue by using processed jobs in a session of duration $\mathrm{T}$ under multiprocessor environment. These kind of estimates are useful when sudden failure (or breakdown) of system occurs and backup management required.

\section{REFERENCES}

[1] Carl A. Waldspurger William E. Weihl: Lottery Scheduling a flexible proportional-share resource management, Proceedings of the $1^{\text {st }}$ USENIX Symposium on Operating Systems Design and Implementation (OSDI),pp.1-11, 1994.

[2] Cochran, W.G: Sampling Technique, Wiley Eastern Publication, New Delhi 2005.

[3] David Petrou, Garth A. Gibson, and John W. Milford: Implementing Lottery Scheduling: Matching the specializations in Traditional Schedulers, Proceedings of the USENIX Annual Technical Conference USA, pp.66-80, 1999.

[4] Raz, D., B. Itzahak, H. Levy: Classes, Priorities and Fairness in Queuing Systems, Research report, Rutgers University, 2004.

[5] Shukla, D. and Jain, Saurabh. : A Markov chain model for multilevel queue scheduler in operating system, Proceedings of International Conference on Mathematics and Computer Science, ICMCS-07, pp. 522-526, 2007.
[6] Shukla, D. and Jain, Saurabh: Deadlock state study in security based multilevel queue scheduling scheme in operating system, Proceedings of National Conference on Network Security and Management, NCNSM-07, pp. 166$175,2007$.

[7] Shukla,D.and Jain, Anjali, Choduary Amita: Estimation of ready queue processing time under SL scheduling scheme in multiprocessor environment, International Journal of Computer Science and Secucity (IJCSS),4(1) pp. 74-81, 2010.

[8] Silberschatz, A. and Galvin, P.: Operating System Concepts, Ed.5, John Wiley and Sons (Asia), Inc. 1999.

[9] Singh, Daroga and Choudhary F.S.: Theory and Analysis of Sample Survey and Designs, Wiley Eastern Limited, New Delhi, 1986.

[10] Stalling, W.: Operating System, Ed.5, Pearson Education, Singapore, Indian Edition, New Delhi, 2004.

[11] Tanenbaum, A.: Operating system, Ed. 8, Prentice Hall of India, New Delhi, 2000. 